\title{
Presencia, evolución y significado de las imágenes de mar en la obra poética y narrativa de Joseba Sarrionandia (1981-2001)
}

\author{
Eider RODRÍGUEZ MARTÍN \\ Departamento de Didáctica de la Lengua y Literatura \\ $\mathrm{UPV} / \mathrm{EHU}$ \\ eider.rodriguez@ehu.es
}

\begin{abstract}
RESUMEN
A lo largo de toda la obra de Joseba Sarrionandia, compuesta por más de 25 libros de diversos géneros, puede encontrarse un conjunto de imágenes que se repite con tesón: se trata de las imágenes vinculadas al mar.

En este trabajo hemos querido analizar la presencia, evolución y significado de las imágenes de mar en la obra poética y narrativa de Joseba Sarrionandia desde el año 1981 hasta el 2001, trayendo a la superficie lo que subyace en ellas y proponiendo así nuevas lecturas de su obra.
\end{abstract}

Palabras clave: Literatura, Sarrionandia, mar, símbolo.

[Recibido, septiembre 2014; aprobado, diciembre 2014]

Presence, evolution and meaning of sea images in poetic and narrative work of Joseba Sarrionanandia (1981-2000)

\begin{abstract}
Joseba Sarrionandia has published more than 25 books in various genres; and throughout the weave of his tapestry, a group of images constantly reappear: images related to the sea.

In this work we wished to analyze the presence, the evolution and the meaning of these images during Sarrionandia's narrative and poetry between 1981 and 2001. We wish to bring to the surface what exists beyond the bare text, behind the images and suggesting new interpretations.
\end{abstract}

Keywords: Literature, Sarrionandia, sea, symbol. 


\section{Introducción}

En toda la obra de Sarrionandia pueden encontrarse ejemplos de libros que hacen referencia al mar: tanto en traducciones (Izkiriaturik aurkitu ditudan ene poemak [Poemas míos que he encontrado escritos], Marinela [El marinero] de Pessoa, Poemas náufragos. Galegoz heldutako poemak [Poemas náufragos. Poemas llegados en gallego], Marinel zaharraren balada [La balada del viejo marinero] de Coleridge o Antologia. Manuel Bandeira [Antología: Manuel Bandeira], por ejemplo) como en ensayos ( $\mathrm{Ni}$ ez naiz hemengoa [No soy de aquí] ${ }^{1}$, Marginalia, Ez gara geure baitakoak [No somos de nosotros mismos]), como en colecciones de poemas (Marinel zaharrak [Viejos marineros] o Hnuy illa nyha majah yahoo. Poemak 1985-1995²), así como en obras de narrativa (sirvan como ejemplo Narrazioak [Narraciones] $]^{3}$ o Lagun izoztua [El amigo congelado]).

Resulta llamativa la obstinación que muestra el autor hacia el mar y hacia diversos elementos que no podrían existir sin el mar, como pueden ser el puerto, la playa, el barco, el marinero, la gaviota, el náufrago, el cuaderno de bitácora, etc. La abundancia de estas imágenes nos lleva a pensar en significados no literales. Y es que el mar de Sarrionandia no es un simple recurso colorido, ni un paisaje ora salvaje ora de desesperanza que sirva de atrezzo, sino una imagen cargada de significados que anida en lo profundo de sus obras. De la red que conforma el conjunto de su obra se derivan los significados no literales del mar, imprescindibles para traer a la superficie las dimensiones ocultas de la obra de Sarrionandia.

Para llevar a cabo este trabajo hemos analizado las imágenes relacionadas con el mar de la obra narrativa y poética publicada entre los años 1981 y 2001. A la hora de limitar el corpus, hemos querido poner en un extremo su primera obra publicada (Izuen gordelekuetan barrena [A través de los escondites del miedo], 1981) y en el otro su primera novela (Lagun izoztua, 2001), ya que en el caso de la primera pueden observarse los primeros rastros del imaginario marino, y en el caso de la segunda porque en ella pueden encontrarse la evolución y el cenit de dicho imaginario.

A través de la interpretación de estas imágenes quisiéramos ofrecer nuevas claves para leer la obra de Sarrionandia desde otras perspectivas.

\section{Joseba Sarrionandia y la imposibilidad del lenguaje}

Los miembros de la Banda Pott ${ }^{4}$ se sentían preocupados por el deterioro del lenguaje, y siendo Sarrionandia uno de los miembros más significativos de este grupo literario, dedicó numerosas páginas a reflexiones en torno a los límites y taras del lenguaje. He aquí varios ejemplos:

\footnotetext{
${ }^{1}$ (1991) No soy de aquí, Fuenterrabía: Hiru (traducción al castellano de Bego Montorio).

2 Título tomado de la cuarta parte de Los viajes de Gulliver de Jonathan Swift, que en el idioma de los houyhnhnms significa "Ten cuidado, buen yahoo".

${ }^{3}$ Traducido al catalán: (1986) Narracions, Barcelona: Editorial Portic (traducción de Josep Daurella).

${ }^{4}$ Grupo literario iconoclasta y vanguardista surgido en 1977 en Bilbao en torno a la revista del mismo nombre, de la cual publicaron seis números. La banda estuvo compuesta por Bernardo Atxaga, Ruper Ordorika, Jon Juaristi, Manu Ertzilla, Joxemari Iturralde y Joseba Sarrionandia, y tuvo gran impacto en la escena literaria vasca. Se deshizo en 1980 sin llevar a cabo el cometido de crear una editorial.
} 
Friedrich Nietzsche decía que no hay razón en el lenguaje, que el lenguaje es una vieja embaucadora, y que mientras sigamos creyendo en la gramática no ahuyentaremos la idea de Dios, no superaremos nuestras estrechas limitaciones (1985a: 163$)^{5}$.

Y:

Friedrich Nietzsche proponía en su ontología el lenguaje metafórico. En su opinión el lenguaje dogmático de los conceptos no es capaz de captar la mutación y la integridad de las cosas. (...) El conocimiento científico ya no es material sino simbólico (1985a: 177) ${ }^{6}$.

Por un lado, Sarrionandia muestra el carácter limitado del lenguaje y la desconfianza que este le merece; por otro, apunta a la utilización de un lenguaje metafórico y simbólico para superar este obstáculo. En efecto, para un escritor tan convencido del deterioro y las limitaciones del lenguaje, la utilización del lenguaje metafórico y simbólico resulta una vía de escape. Así, partiendo del significado "oficial" de las palabras (nos referimos al significado enciclopédico de las palabras, además de a la carga histórica que recae sobre ellas), lo adecua para tejer una nueva red de significados. Para alguien cuya herramienta de trabajo son las palabras, constituye un gran desafío dotar a esas palabras de nuevos significados, texturas y pliegues.

También se refiere de otra manera a esto que asume como tarea propia:

La labor del poeta, como dijo Stéphane Mallarmé, es dar un sentido más claro a las palabras de la tribu. Un sentido más limpio, más completo, más profundo, para crear por medio de las palabras unas relaciones más adecuadas entre la conciencia y el mundo, para conseguir un conocimiento nuevo más verdadero de las cosas y las situaciones.

El objeto de la poesía es la vida, y el mundo, ese itinerario medio conocido medio indiscernible que llevamos. Si intentamos enmendar nuestro desarrapado lenguaje, si nos esforzamos en hallar palabras más ciertas, es para deshacer las fronteras de las falsas certitudes, para conocer mejor nuestra vida en la tierra y para, conociéndola, disfrutarla (1985a: 168-169) ${ }^{7}$.

Multiplicar las palabras de la tribu, esforzarse por buscar palabras más verdaderas detrás de las falsas, revivir el habla muerta, darle una nueva vida... Sarrionandia no empleará una única vía para conseguir este objetivo: hará uso de alegorías (2008), de diccionarios (1997), pero sobre todo de metáforas y de símbolos. Para llevar a cabo esta tarea, sin embargo, Sarrionandia necesitará la complicidad de sus lectores. Más de una vez se ha dirigido a sus lectores avisando sobre lo pertinente de leer el reverso de las palabras, lo oportuno de huir (1985a: 26) del mundo de los sentidos prefabricados, la necesidad de tratar de encontrar otro sentido a las palabras y, sobre todo, al lenguaje, lejos de representaciones congeladas (1985a: 25). Ya que las palabras no son neutrales, "las palabras, las palabras que llegan hasta nosotros, se nos dan ya cargadas de historia" $(1985: 31)^{8}$. Por ello, azuza al lector para que mire más allá de la superficie, o, como respondió el narrador de cuentos en el prólogo del diccionario Hitzen ondoeza [El malestar de las palabras] a la petición de explicar el cuento:

\footnotetext{
${ }^{5}$ Traducción de Bego Montorio (1995), No soy de aquí, Hernani: Editorial Orain.

${ }^{6}$ Ídem, p. 117.

7 Ídem, p. 112.

${ }^{8}$ Ídem, p. 26.
} 
- ¿Qué te parecería si alguien te ofreciera una nuez y si esa nuez te la diera masticada de la boca a la mano?

- ¡Masticada no! -respondió un oyente.

(...)

- Nunca masticada, entonces. Sin cáscara solo para los niños y para los enamorados. Para el resto, con cáscara incluida (1997: 9).

Sin duda, el eje en torno al que girará la labor de Sarrionandia de multiplicar las palabras de la tribu, de este empeño por superar los límites del lenguaje, lo constituirán las imágenes relacionadas con el mar. De poema en poema, de relato en relato, en definitiva, de obra en obra, empleará el impulso que por tradición contienen las imágenes del mar para formar una nueva y densa red de significados. Es en este sentido en el que Sarrionandia cita a Roland Barthes: "La palabra texto viene de textus, del participio pasado del verbo texere, que significa tejer: El texto es un tejido de significados unidos" (1985a: 27). En este gran tapiz compuesto de textos que es su obra, encontraremos metáforas y símbolos construidos con gran cohesión y coherencia, que servirán para desafiar al lenguaje, a ojos de Sarrionandia marchito, y para reflexionar sobre la realidad más prosaica; en este caso, sobre la realidad histórico-política que representa la red de imágenes del mar y de las realidades individuales derivadas de ella.

En definitiva, aquel diálogo fascinante que escribió Lewis Carroll y que recogió Sarrionandia ${ }^{9}$ señala una de las claves del límite del lenguaje que tanto preocupan al escritor vizcaíno: en concreto, el de la propiedad de las palabras. Ya que quien sea dueño de las palabras, también lo será de sus significados. Quien escriba los diccionarios, será quien ordene de qué significados se dotará a las palabras. Huyendo de ese monopolio de significados, ayudado por símbolos y metáforas, así como por diccionarios y alegorías, Sarrionandia aboga por un modo más libre y menos contaminado para reflexionar en torno a la realidad.

\section{Evitando el yo}

A la desconfianza hacia el lenguaje hay que añadir otro tema que es una constante en la poética de Sarrionandia: se trata de la necesidad de evitar el yo. De hecho, en el caso del escritor vasco su biografía tiene un peso inusual a la hora de determinar su texto ${ }^{10}$ : adoles-

\footnotetext{
9 "Cuando yo digo una palabra -dijo Humpty Dumpty- significa lo que yo quiero que signifique, ni más ni menos". "El problema - dijo Alice- es el siguiente, saber si usted puede conseguir que las palabras signifiquen tantas cosas diferentes" (Sarrionandia, 1985a: 162; traducción de Bego Montorio, op. cit.: 108).

${ }^{10}$ Landa (1990): "Los libros de Sarrionandia que nos llegan como botella de náufrago no pueden sino ser bien acogidos por los lectores. Porque es la única manera de reducir la obligada lejanía"; Epaltza (1994): "La admiración que genera la figura del escritor militante tiene, más que seguramente, algo que ver con las nueve ediciones de este que se han publicado hasta ahora"; Amézaga (2002): "Leyendo Lagun izoztua nos viene a la mente una y otra vez la experiencia personal de este conocido escritor, la del refugiado Joseba Sarrionandia, la de un famoso autor que vive escondido en este mundo"; Bergara (2002): "Este año el escritor de Iurreta cumplirá diecisiete años en el exilio, y le ha salido una novela del exilio. (...) Como señaló el autor (...) en una entrevista concedida, 'aunque no es autobiográfica, aún haciendo ficción, me he sentido implicado en los personajes y en las situaciones'. Saber esto, por supuesto, hace más cruda su lectura"; Egaña (2005): "Es sabido que la atractiva biografía de Sarrionandia y la afinidad ideológica le han dado al escritor de Iurreta una lealtad incondicional de amplios sectores entre los lectores. (...) En definitiva, el resultado, al margen de los elementos ajenos al texto arriba señalados (biografía, ideología,
} 
cente en los primeros años de la década de los setenta del siglo XX, entró a formar parte de ETA en su juventud, por lo que fue detenido y encarcelado. En 1985 consiguió huir de la prisión. Desde entonces, vive en la clandestinidad, probablemente en algún país de América Latina. Sin embargo, y desde sus inicios, Sarrionandia se ha mostrado muy pudoroso a la hora de mostrar su yo, cobijándose en la idea de comunidad, en la primera persona del plural. Y es que para los integrantes de Pott, uno de los criterios de la concepción de la modernidad literaria consistía en no referirse jamás al yo: lo que uno desea no es importante, las circunstancias de un individuo no han de tenerse en cuenta, la vida de uno es vacua. Esta autoprohibición para hablar del yo (Azkorbebeitia, 2002), como la define otro de los integrantes y creadores de Pott que fue Bernardo Atxaga, hace que durante casi la totalidad de toda su obra, Sarrionandia eche mano de elementos paratextuales (prólogos, epílogos, portadas, entrevistas...) y de códigos simbólicos para hacer referencia a su situación personal, esquivando siempre hablar de ella en primera persona y de forma literal.

\section{La evolución de las imágenes del mar en las obras de poesía y narrativa (1981-2001)}

A continuación, analizaremos la presencia, evolución y significado de las imágenes del mar en las obras de poesía y narrativa de Sarrionandia del período 1981-2001.

En el libro de poesía Izuen gordelekuetan barrena (1981) las imágenes del mar son numerosas. El mar que aparece en este poemario representa la vida, o la imagen que, en aquella época, tenía Sarrionandia sobre la vida. Publicado mientras se encontraba en la cárcel pero escrito antes de haber sido detenido, el mar es aventura, cosmopolitismo y búsqueda de la Verdad, pero, sobre todo, el mar muestra la vía para huir de su pequeña patria. El libro tiene estructura de viaje a través del mar, un viaje dividido en siete escalas. Además, será símbolo de apertura a la literatura universal, ciñéndose así plenamente a la perspectiva intertextual de la Banda Pott. En este sentido, quisiéramos señalar que en este libro Sarrionandia hace mención a varios escritores y que, aunque se trate de su primera obra, muchos de ellos no le abandonarán en toda su andadura literaria, como por ejemplo Coleridge, Melville, Conrad, Swift o Schwob. Además del mar, también están los siguientes espacios de indeterminación que con frecuencia aparecen en su obra: el marinero, el barco, la playa, el náufrago y el puerto. En este primer libro, la playa aparece ya como lugar de descanso y el puerto como lugar inerte y desconchado, pasto del pasado. Además, el marinero es alguien que, a pesar de saber que va a naufragar, encuentra la suficiente fuerza para partir a la mar, alguien íntegro; el barco está constituido por una comunidad consciente de que va a compartir el dolor y la libertad. Sarrionandia prevé desde su primer libro de poemas el sufrimiento que le va a suponer su integración en ETA, ya que se involucra a sabiendas de que va a naufragar.

En la colección de narraciones Narrazioak [Narraciones] (1983b) y tal y como hizo en Izuen gordelekuetan barrena, Sarrionandia evita convertir su situación personal en tema literario. Atxaga, en el epílogo que forma parte del paratexto, se refiere a esta "situación personal" como "lo visto tras haber ido mar adentro por el camino de plata". Esta colección de relatos fue escrita en prisión, y de diez narraciones tres están localizadas en el mar,

mitificación...), es un texto que a duras penas funciona, que juega con la complicidad apriorística del lector para conmover"...etc. 
siendo en las otras siete abundante la utilización de imágenes relacionadas con ese ámbito. Podríamos decir que el autor todavía se muestra fuerte con respecto al mar, dispuesto a reconstruir la nave con los restos en caso de naufragar, aun sabiendo que después de cada nuevo naufragio el barco será más precario y el marinero más viejo; el mar seguirá impertérrito a lo acaecido a su alrededor, y así es como se nos presenta: inmortal y sin perder un ápice de su fuerza. Podríamos decir que el mar es representado como el trasunto de la lucha y el marinero como un miembro que se incorpora a ella. "En el trasunto de la lucha que es el mar, ¿de qué sirve la literatura?", es la pregunta que se nos hace implícitamente. Tal y como expresa la imagen del marinero que envía botellas vacías desde una isla, parece ser que a Sarrionandia se le está quedando pequeña la literatura como juego y viaje estético.

La colección de cuentos Atabala eta euria [El tambor y la lluvia] (1986) es el primer libro publicado tras la huida de Sarrionandia; sin embargo, aquí la fuga no es, en modo alguno, sinónimo de libertad. Aparecen ya los miedos y fantasmas del hecho de haberse embarcado y, por primera vez, el autor pondrá en duda el carácter de ese barco que representa a ETA o a la lucha armada. Asimismo, desde el mismo título asociará el haber optado por el mar con la juventud y con su consiguiente candidez. La narración del mismo nombre trata sobre un niño que está tocando el tambor: aunque llueve a cántaros, el niño, sin dejar de tocarlo, seguirá el rumbo del agua, dejará que el agua le moje, se comprometerá, hasta que ese agua se convierta en diluvio y después en mar. Pero para entonces nadie escuchará el grito de ese niño que esta abocado a ahogarse.

El cruce del título del poemario Marinel zaharrak [Viejos marineros] (1987) con nuestro horizonte literario nos trae a la mente La balada del viejo marinero de Coleridge, que, como anteriormente hemos mencionado, el autor que nos ocupa tradujo al euskera (1995b). Tal y como Sarrionandia recuerda en el prólogo: "nuestras historias son historias de viejos marineros, para contárselas a la gente que va sin apenas tiempo de escuchar lo que decimos". Vuelve la idea de comunidad, retraída tras ese nosotros, evitando otra vez referirse al yo. No obstante, también hay, dentro de ese nosotros, pequeñas referencias al yo: este viejo marinero tiene el corazón dividido: una mitad está libre, la otra, por el contrario, está presa, es incapaz de desprenderse del encarcelamiento y del exilio. Persiste el conflicto entre la vida y la literatura que aparecía en los libros anteriores, tal y como recoge el bello poema "Literatura eta iraultza" (Literatura y revolución). Marinel zaharrak habla sobre las razones para hacerse a la mar, y en esta ocasión también alude a la falta de alternativa, dado que el mar, como la poesía, es una fatalidad. En este libro hay un poema que nos resulta especialmente elocuente. Se trata de "Itsaso debekatuak" (Mares prohibidos), y dice así: "¿De dónde vienen los marineros? ¿A dónde va el barco? ¿Por qué? ¿Quiénes son los marineros? ¿Qué es el barco?". A nuestro juicio, mediante estas preguntas Sarrionandia aboga por ir aclarando sus preocupaciones y sus dudas acerca de su militancia a través del diálogo con el lector, y resulta difícil no determinar las imágenes del mar presentes en el horizonte interno de la obra del autor vizcaíno, que si bien hasta ahora podían haber sido difusas, exigen con creciente claridad nuevos significados e interpretaciones.

La colección de narraciones Ifar aldeko orduak ${ }^{11}$ [Horas del norte] (1990) trata principalmente del dolor que produce la imposibilidad de volver a la tierra natal. Donde con más

\footnotetext{
${ }^{11}$ Juego de palabras con Iparralde, País Vasco del norte.
} 
nitidez se siente esta emoción es en la narración "Ifar aldeko nasa" (Puerto del norte). Aquí entra en escena una nueva imagen de mar: la nieve y el posterior hielo. El protagonista de este relato se llama Ismael Larrea, nombre del joven que huía en la colección de cuentos precedente, lo que nos lleva a verlo como heterónimo de Sarrionandia. El mar se ha convertido en algo que sucede ante Ismael porque él, ahora, está en tierra, en un trozo de tierra helado. El mar que tiene delante es frío, triste, desolado, salvaje e infinito. En nuestra opinión, el autor denuncia una situación de stand by, un punto intermedio que no es ni mar ni lucha, pero que tampoco es tierra firme ni ausencia de lucha; el exilio, en definitiva. Tanto esta narración como la colección hacen referencia a la primera época del exilio que vivió Ismael, Sarrionandia, en Ifar aldea, es decir, en el norte del País Vasco. En esta colección de relatos se subraya la vigencia del diálogo en torno a la lucha armada iniciado en Marinel Zaharrak, y por primera vez se habla de equivocación: la equivocación de aquellos que a pesar de su generosidad se embarcaron sin medir bien sus fuerzas.

Gartzelako poemak [Poemas de la cárcel] (1992a) nos lleva a pensar en la autobiografía, por los elementos paratextuales del libro y por la biografía del autor, inserta en nuestro horizonte vital. Aquí pueden leerse las mismas preguntas planteadas en Marinel Zaharrak, pero esta vez hemos encontrado posibles respuestas en el horizonte interior del propio texto: por muy hermoso que fuera el sueño perseguido al hacerse a la mar, no se ha conseguido lo buscado y lo que es peor, el sueño también se ha perdido en el camino, o, como dice el propio Sarrionandia: "hemos sembrado sueños/para cosechar sueños" pero ahora "no tenemos nada". No en vano "Itsaso debekatuak" vuelve a aparecer en este poemario: se trata del mismo poema, las imágenes también son las mismas, pero ha pasado tiempo desde la primera vez que lo publicó, y seguramente, el paso del tiempo también ha incidido en la manera de determinar dichas imágenes y responder las preguntas relativas a la lucha armada. El viaje a través del mar iniciado en Izuen gordelekuetan barrena se ha convertido en viaje a través del dolor. En Gartzelako poemak el escepticismo y el cansancio cobran aún mayor dimensión, y si en la obra anterior las playas eran un espacio de disfrute y los puertos un hito del posible regreso, ahora tanto las playas como los puertos han dejado de ser un lugar del soñado descanso para convertirse en puro recuerdo.

El libro de poemas Hnuy illa nyha majah yahoo (1995) nos trae dos nuevas imágenes relacionadas con el mar. La primera viene dada en numerosas ilustraciones y presta su nombre a un capítulo del libro: los nudos marineros. Las preguntas sobre el carácter, los objetivos y el futuro de ETA siguen sin respuesta, y Sarrionandia insiste en la necesidad de deshacer esos nudos, los cuales son preguntas vinculadas al carácter y al rumbo del barco. En el viaje marino que al principio resultaba ser la militancia, el rumbo no era una cuestión clara, porque lo importante era partir, sin miedo al naufragio. Pero, a medida que pasan los años, el marinero ha ido entristeciéndose y curtiéndose, y el naufragio ha sucedido, no solo el de Sarrionandia sino el de otros muchos. En el poema "Itsasoak emandako indarra" [La fuerza dada por el mar], el poeta trata de recordar la fuerza que impulsa a la gente a hacerse a la mar y confiesa que él ya no tiene vigor y que incluso le resulta difícil rememorar aquel misterio que lo lanzó a navegar. La segunda se refiere a los nuevos mares. En el poema "Untzigintza"[Construcción naval], Sarrionandia propone inventar nuevos mares, y en esta imagen, tal y como podremos determinar tras la lectura de Lagun izoztua, anida la demanda de inventar nuevos espacios de lucha.

Lagun izoztua (2001): Hemos analizado esta novela tomando en consideración los tres planos en los que las imágenes de mar aparecen espacial y cronológicamente separadas. En 
Lagun izoztua aparecen las imágenes del mar de todas sus obras anteriores, convirtiendo la evolución plano a plano de dichas imágenes en algo espectacular, además de significativo. Estos planos son Kalaportu, el plano compuesto por Centroamérica y Sudamérica, y la Antártida.

En el plano de Kalaportu nos encontramos un mar cargado de señales y premoniciones, que advierte de los peligros históricos de hacerse a la mar: el tío de Goio, del que también lleva el nombre, fue tragado por el mar, y por mar vino y se fue el padre que Goio no conoció. Al mismo tiempo, el mar de Kalaportu es un espacio para respirar ante la estrechez de la tierra y la represión, el espacio donde se suceden las aventuras, la puerta que se abre al mundo, la libertad y el campo de batalla, desde la Guerra Civil hasta la década de los setenta donde se asienta este plano ${ }^{12}$. Así, huyendo del internado, los jóvenes Goio y Andoni irán asiduamente al mar, cuya fuerza de atracción los pondrá al límite del misticismo. En gran medida, y gracias a la coartada que le ofrece la mirada adolescente de los personajes principales, el mar de Kalaportu se asemeja al mar romántico de Izuen gordelekuetan barrena, y provoca una atracción indómita en los jóvenes turbados por la cerrazón y la angustia del franquismo. Las orillas de Kalaportu serán lugar iniciático y el mar la escuela para hacerse hombres, porque los jovencitos se sienten hombres subidos al batel y porque desde ahí dominan mejor el juego de seducción con las chicas que están en la playa. Sin embargo, en Kalaportu ha empezado a darse una vaga feminización del mar. En las obras precedentes, las playas eran el lugar donde se ubicaban los personajes femeninos, fuera en el papel de chica joven, de sirena o de amante, y el mar era espacio de hombres. En Lagun izoztua aparece una mujer, Ariane, que ocupará tanto la playa como el mar. Por primera vez en la obra de Sarrionandia, aparecerá una mujer que milita en ETA, quien andará por el mar y por la orilla con toda naturalidad. Kalaportu, además de plantear las motivaciones que llevaron al joven Sarrionandia a hacerse a la mar, a comprometerse, es el contrapunto que suponía en aquel ambiente represivo el mar o la organización armada ETA, y, como indica el tiempo verbal, pertenece al pasado.

Los mares que aparecen en el plano de Centroamérica y Sudamérica son muy diferentes al mar de Kalaportu. Los protagonistas del plano de Kalaportu, Andoni y Goio, viven aquí, exiliados tras haber puesto rumbo al mar tiempo atrás. Y, paradójicamente, a pesar del calor y del clima tropical, Goio se ha congelado, está en situación de stand by, estático; no está ligado a la lucha que conlleva estar en el mar, pero tampoco está desligado de ella, sino en un punto intermedio, en el exilio. En este plano, el muelle está putrefacto y enmohecido y el mar tiene aspecto de sopa tibia, siendo pantanoso y tranquilo, dibujando un paisaje decadente. Los barcos, además, son botes cada vez más destartalados. Han desaparecido el deslumbramiento y la curiosidad por el mar, no hay magia ni misticismo alguno en sus aguas. El mar ya no es un lugar únicamente para hombres: las mujeres andan con naturalidad no solo por las playas sino también por el mar, incluso como guías. Es, de entre los tres planos, el que menos imágenes del mar contiene. Como puede observarse en la evolución de su obra, cuanto más cercana está la ficción del presente de Sarrionandia, más exiguas son las imágenes relacionadas con el mar.

\footnotetext{
${ }^{12}$ El campo de batalla que representa el mar se subraya constantemente, y nos parece especialmente destacable el ejemplo de las pistolas: el mar guarda las pistolas de la Guerra Civil, pero también las de ETA.
} 
El mar de la Antártida es totalmente diferente: el que se nos muestra poco antes de que Goio parta hacia la Antártida es triste, frío, solitario y desolado, parecido al de "Ifar aldeko nasa". Una vez embarcado, la descripción no hará más que endurecerse: narrado en futuro, nos mostrará un mar que irá congelándose, que pondrá cada vez más obstáculos para el avance, que los icebergs irán paulatinamente haciendo más vertical, un mar que no hará posible la vida. Por lo tanto, al barco, construido para la horizontalidad, se le hará difícil navegar, y a la tripulación, a los miembros de ETA, cada vez más adversa la supervivencia. El nombre del barco que va a la Antártida es Iron will, Espíritu de Hierro o Voluntad de Hierro, porque de esa pasta tiene que ser el espíritu del que allí navega. El barco está cargado de dolor y de preguntas que duelen, o así lo refleja el conjunto de preguntas que Goio encuentra en una nota de un libro: "¿Por qué estoy haciendo este viaje? ¿Qué estoy dejando atrás?"...etc. Esta nota podría constituir la continuación de las cuestiones lanzadas en el poema "Itsaso debekatuak" del libro Marinel zaharrak (¿A dónde va el barco?, ¿por qué?, etc.). Son preguntas que promueven la reflexión en torno al carácter y la evolución, presente y pasados, del barco, de la lucha armada.

El mar de la Antártida transmite un frío absoluto; no solo un frío relativo a la temperatura, sino un frío científico que impide la empatía humana: porque en este plano el mismo mar es objeto de una expedición científica, y porque los convocados no son simples marineros sino cartógrafos, científicos, etc. El entusiasmo, la atracción y la espontaneidad que inspiraba el mar de Kalaportu no aparecen, y, en cambio, se impondrá la atmósfera desilusionada de "Ifar aldeko orduak". El mar de la Antártida no es romántico, sino un espacio lleno de abatimiento y gente enferma.

Otra imagen que nos resulta reveladora en el plano de la Antártida es la del barco a la deriva, que podría representar a ETA de concretizarla según los parámetros del horizonte interior de la obra de Sarrionandia. Finalmente el barco se detendrá, porque una fuerza más poderosa que él, en este caso la fuerza natural que representa el hielo, no le dejará avanzar ni retroceder. La tripulación quedará a la espera del grupo de salvamento, y mientras espera su lucha se reducirá a la supervivencia. Tan pronto como salgan de allí, cada cual tomará su camino individual, según la voluntad, las posibilidades y las necesidades propias, y deshaciendo la comunidad que materializaba el barco.

El mar helado de la Antártida, en definitiva, se ha convertido en espejo, en oportunidad para vérselas con uno mismo, siendo contra uno mismo la lucha que ahí se libra. A partir de ahí, frente al espejo, Sarrionandia ha hecho su elección, tal y como adelantaba en su último libro de poemas y tal y como ratifica al final de esta novela: seguir inventando nuevos mares, o, por decirlo sin metáforas, inventar nuevas maneras de construir su país, al margen de ETA.

\section{Conclusiones}

Las imágenes de mar en la obra poética y narrativa de Sarrionandia entre 1981y 2001 son una invitación a reflexionar sobre el tan mediatizado conflicto vasco sin caer en las trampas del lenguaje, lejos del ámbito del significado oficial de las palabras y a través del nuevo "lenguaje de la tribu". Proponen, además, la oportunidad de reflexionar, recuperando la antigua costumbre del diálogo, en torno a preguntas como qué es el barco, a dónde va, $u$ otras sobre la congelación del mar, la incapacidad del barco y la situación de la tripulación, siempre lejos del yo del autor y promoviendo en la medida de lo posible la vía del razonamiento colectivo. 
En este artículo hemos investigado veinte años de la obra poética y narrativa de Sarrionandia, viendo de cerca la evolución habida desde el mar bravío e intenso de sus inicios hasta el mar helado de Lagun izoztua, donde cada vez es más difícil vivir. Aquel mar del pasado, aquel método de lucha se ha agotado, ha perdido el sentido, y hay que entender la invitación que hace Sarrionandia para inventar nuevos mares como alternativa a ese mar que de seguir en él se volverá vertical, frío e inhumano.

\section{Bibliografía}

AMÉZAGA, A. (2002): “Sarriren azken fruitua”, Bilbao, 2002-06.

AzKorbebeitiA, A. (2002): "Sarrionandia irakurriz: han izanik hona da", charla impartida en Bilbo Zaharra Forum, Bilbao.

BERGARA, J. (2002): "Lagun izoztua", Txalaparta, hitzak \& ideiak, 2002-03.

EGAÑA, I. (2005): “Testuak makulua behar duenean”, Berria, 2005-02-08.

EPALTZA, A. (1994): "Narrazioak", Hegats, 1994-01.

LANDA, J. (1990): “Trajedien kronika klabe minorrean”, Argia, 1990-04-20.

SARRIONANDIA, J. (1981): Izuen gordelekuetan barrena, Bilbao: Bilbo Aurrezki Kutxa.

SARRIONANDIA, J. (1983a): Izkiriaturik aurkitu ditudan ene poemak, Pamplona: Pamiela.

SARRIONANDIA, J. (1983b): Narrazioak, San Sebastián: Elkar.

SARRIONANDIA, J. (1985a): Ni ez naiz hemengoa, San Sebastián: Elkar.

SARRIONANDIA, J. (1985b): Izkiriaturik aurkitu ditudan ene poemak, Pamplona: Pamiela.

SARRIONANDIA, J. (1986): Atabala eta euria, San Sebastián: Elkar.

SARRIONANDIA, J. (1987): Marinel zaharrak, San Sebastián: Elkar.

SARRIONANDIA, J. (1988): Marginalia, San Sebastián: Elkar.

SARRIONANDIA, J. (1989): Ez gara gure baitakoak, Pamplona: Pamiela.

SARRIONANDIA, J. (1990): Ifar aldeko orduak, San Sebastián: Elkar.

SARRIONANDIA, J. (1991): Poemas naufragos (Galegoz heldutako poemak), Zarautz: Susa.

SARRIONANDIA, J. (1992a): Gartzelako poemak, Zarautz: Susa.

SARRIONANDIA, J. (1992b): Han izanik hona naiz, San Sebastián: Elkar.

SARrionANDiA, J. (1995a): Hnuy illa nyha majah yahoo (Poemak 1985-1995), San Sebastián: Elkar.

SARRIONANDIA, J. (1995b): Marinel zaharraren balada [The rime of the ancient mariner de T.S. Coleridge], Iruñea: Pamiela.

SARRIONANDIA, J. (1995c): Marinela. Kuadro bakarreko drama estatikoa [O'Marinheiro de Fernando Pessoa], Zarautz: Susa.

SARrionANDIA, J. (1997): Hitzen ondoeza, Tafalla: Txalaparta.

SARrionANDiA, J.(1999): Manuel Bandeira antologia, Pamplona: Pamiela.

SARRIONANDIA, J. (2001): Lagun izoztua, San Sebastián: Elkar.

SARRIONANDIA, J. (2003): Kolosala izango da, Tafalla: Txalaparta. 